\title{
Static and dynamic testing of welded and woven mesh for rock support
}

\section{E. Villaescusa Western Australian School of Mines, Curtin University/CRC Mining, Australia}

A.G. Thompson Western Australian School of Mines, Curtin University/CRC Mining, Australia

J.R. Player Western Australian School of Mines, Curtin University/CRC Mining, Australia

\begin{abstract}
The Western Australian School of Mines has designed, commissioned and extensively used testing facilities capable of subjecting panels of steel wire mesh to static and dynamic loadings. Since commissioning, a large number of tests have been performed on mesh with different wires diameters and apertures. The forcedisplacement responses of the mesh have been measured and then characterised by various performance indicators such as rupture strength, displacement to rupture and energy absorption. The database of test results has been summarised in the form of charts that may be used to easily compare the performance of different mesh configurations and to assist with design of appropriate ground support for static and dynamic loading applications.
\end{abstract}

\section{$1 \quad$ Introduction}

Mesh support is an essential part in providing personnel safe access to underground excavations. It is a form of passive support required to provide surface restraint at an exposed excavation boundary. Rockbolts are likely to control the overall excavation stability through keying, arching or composite beam reinforcing actions, while mesh is installed to support the small, loose pieces of rock detached within a bolting pattern. The mesh loading mechanism can either be uniformly distributed loading forces such as in rock bulking or point loading by loose individual rock blocks (Figure 1). Ultimately, the role of mesh is to respond to significant inward movement of the rock mass surrounding an excavation and to transfer the load to the reinforcement systems (Thompson et al., 2012).
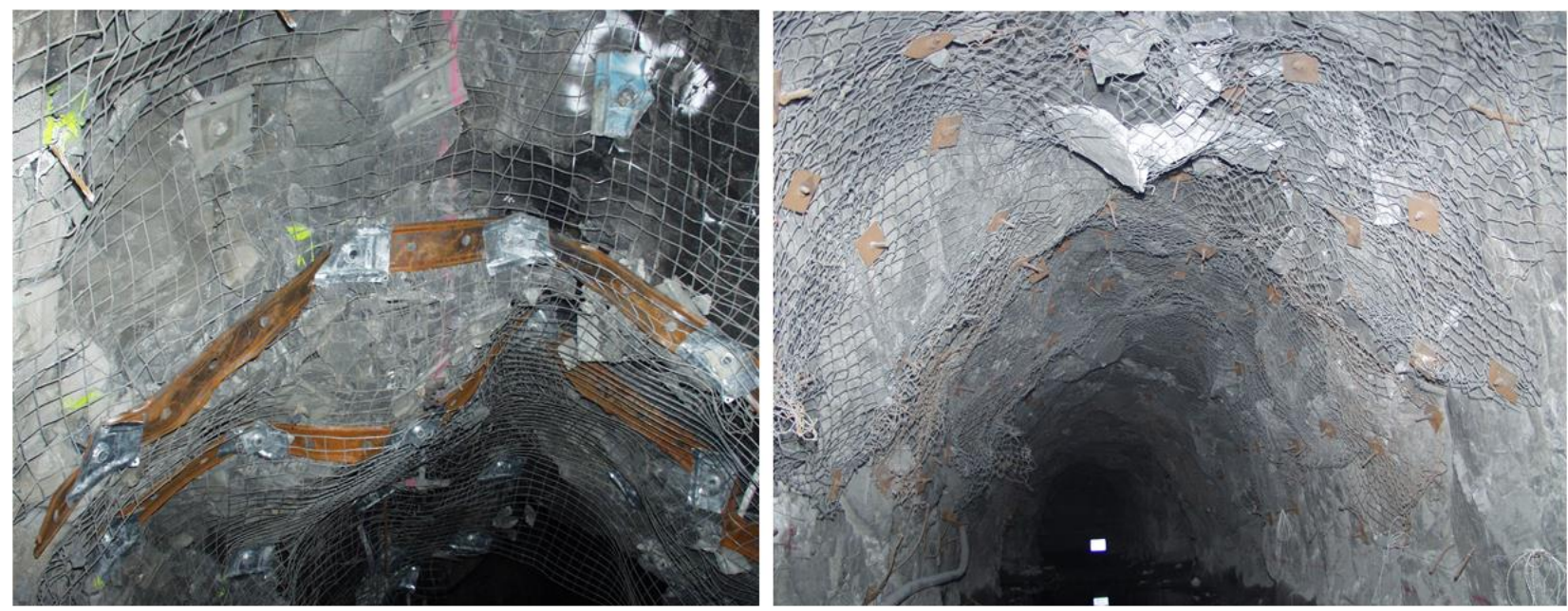

Figure 1 Mesh support in highly stressed rock masses

\section{$2 \quad$ Mesh types}

Steel wire mesh for ground support is available in various configurations. The most common types are welded mesh, consisting of straight wires arranged in a rectangular or square grid and welded together 
and, chain link mesh which consists of regularly bent wires that are woven together and interconnected mechanically (Figure 2).

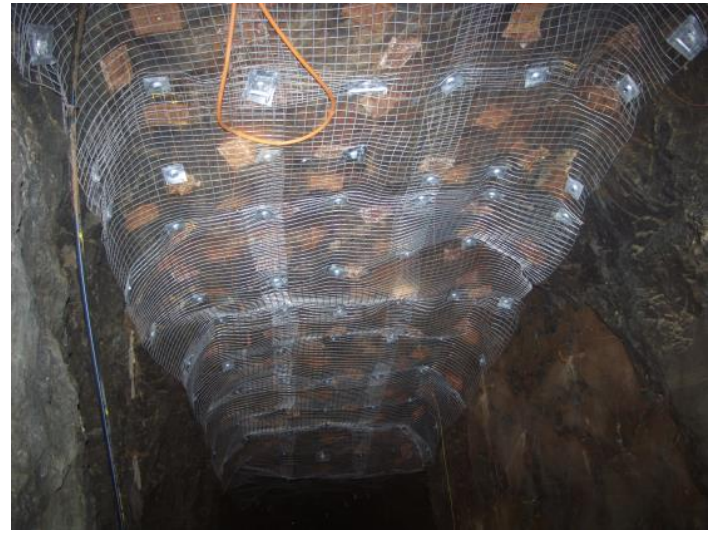

a) Welded mesh

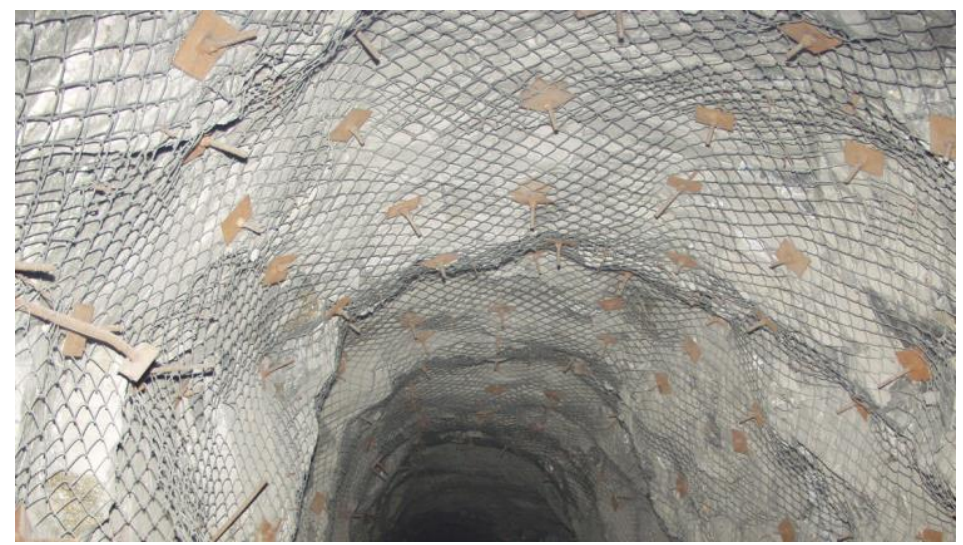

b) Woven (chainlink) mesh

Figure 2 Different types of mesh configurations

The welded mesh may have different wire diameters at different spacings and be supplied in various sheet sizes. The most common configuration consists of $5.6 \mathrm{~mm}$ diameter wires spaced at $100 \mathrm{~mm}$ centres. The wire may have a smooth or deformed profile. These configurations of mesh used for surface support in mines have changed little in the last 25 years or more. The changes (in Australia) have been driven by civil engineering applications and not the mining industry. The changes have mainly been associated with material properties, i.e. yield and ultimate force capacities and elongation capacity, and wire diameters and surface condition, i.e. smooth or deformed wire. The deformed wire has better load transfer capacity than the smooth wire when embedded in concrete slabs. This is also a consideration for mesh reinforced shotcrete, depending on the sequence of mesh then shotcrete or shotcrete then mesh.

Sheets are generally $2.4 \mathrm{~m}$ wide, the maximum that may be specified, with variable lengths, commonly $3.6 \mathrm{~m}$ and up to $6 \mathrm{~m}$. Larger sheets generally cause handling and placement problems. The mechanical handling and installation of welded mesh is shown in Figure 3.

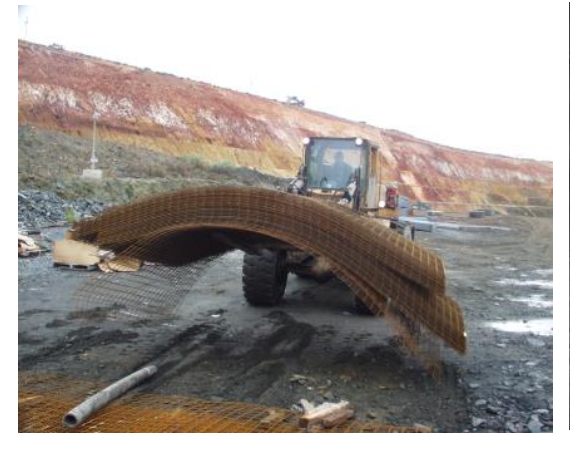

a) Surface storage

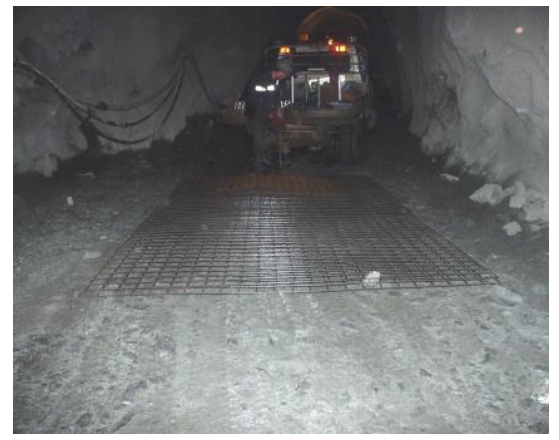

b) Decline transportation

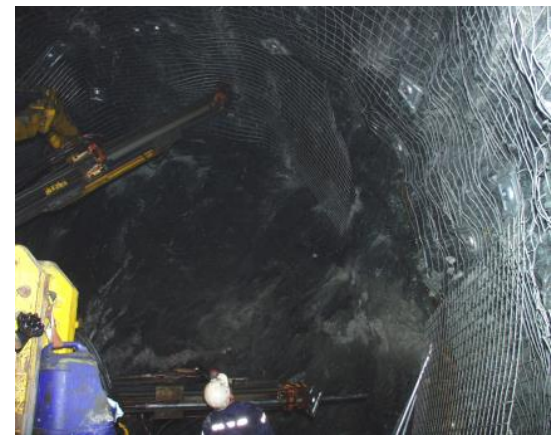

c) Jumbo installation

\section{Figure 3 Mechanical handling and installation of weld mesh}

In the past, rolls of woven mesh required manual installation from either a scissor lift or IT basket (Figure 4). More recently, an automated 'Roll Mesh' handler for the application of high-tensile chain-link mesh was developed and successfully tested in Australia (Coates et al., 2009). The handler is compatible with all commercial multi-boom 'jumbo' drilling equipment, applying mesh from a cassette system. The mesh handler with the mesh roll is mounted on one boom and the drilling/bolting element mounted on the other boom allowing the placement and pinning of the high-tensile mesh simultaneously (Figure 5). 


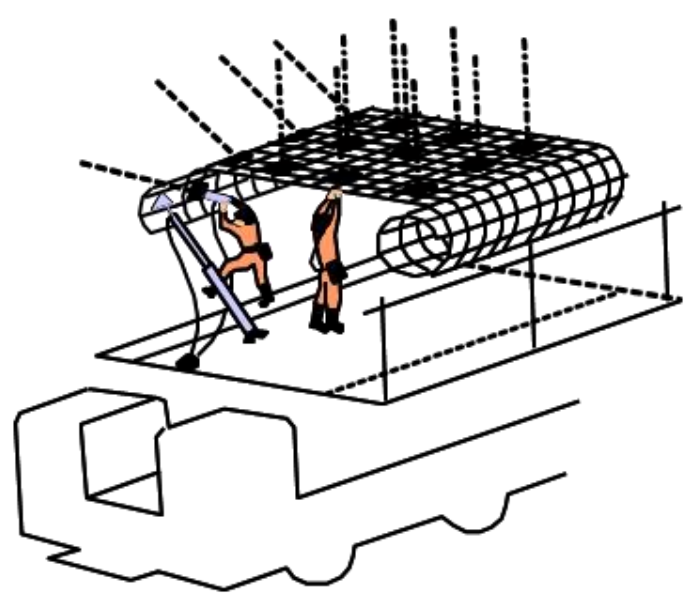

a) Scissor lift

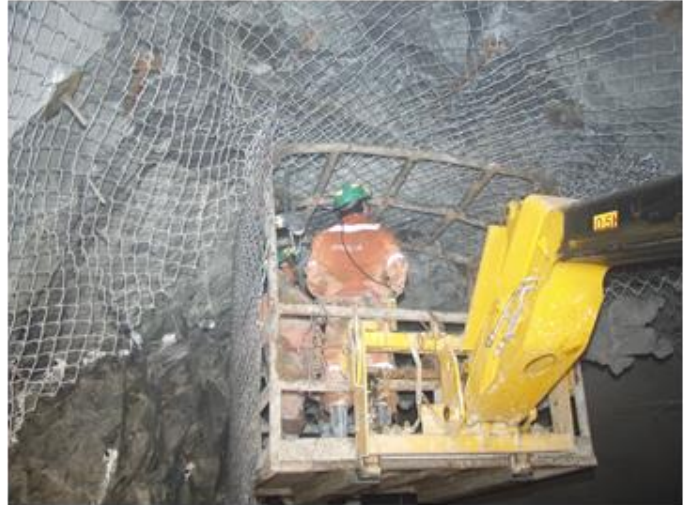

b) IT basket

\section{Figure 4 Manual installation of woven mesh}

The length of the woven mesh can be cut to suit the width of the opening being supported. A perceived problem with this mesh is that it may unravel when one wire is broken. However, this does not appear to have been a problem at mines such El Teniente Mine in Chile. A mesh manufactured by Geobrugg in Switzerland overcomes some of the problems usually associated with woven mesh rolls. The Geobrugg mesh is an assembly of high strength wires that results in mesh that is stiff across the width but can be rolled in the other direction (Roth et al., 2004).
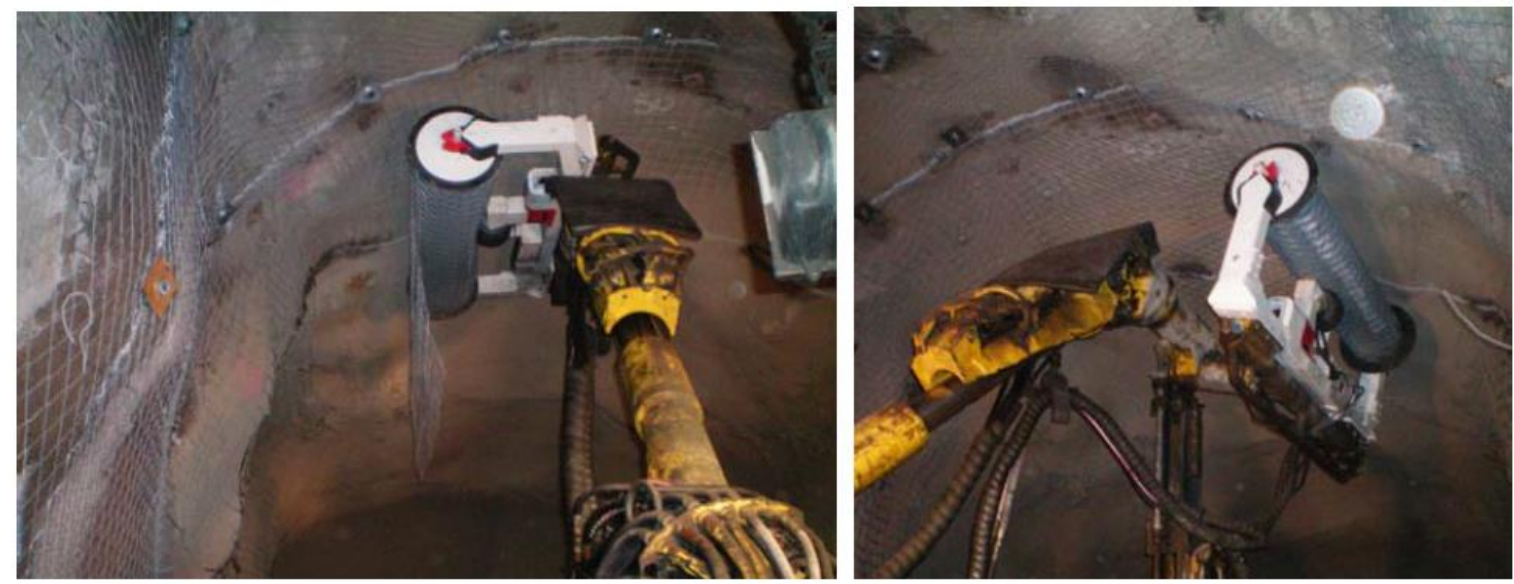

Figure 5 Mechanical installation of woven mesh (Coates et al., 2009)

\section{WASM test facilities}

The Western Australian School of Mines (WASM) has developed facilities for the static and dynamic testing of ground support elements (Player et al., 2008; Morton, 2009). The WASM static facility consists of two steel frames; a lower frame used to support the sample and an upper frame used to provide a loading reaction (Figure 6). A 1.3 by $1.3 \mathrm{~m}$ mesh sample is restrained within a stiff frame that rests on the support frame and the boundary conditions attempt to simulate the continuation of the material beyond the limited sample boundary. The restraint system consists of high tensile bar, eye nuts and D shackles passing through the perimeter support frame at allocated points. A screw feed jack is mounted on the reaction frame. The screw feed jack is driven at a constant speed ( $4 \mathrm{~mm}$ per minute) and allows large displacements to be imposed on the mesh. Load is applied to the mesh through a spherical seat, to a $300 \mathrm{~mm}$ square, $35 \mathrm{~mm}$ thick hardened steel plate. The force is measured using a 50 tonne load cell mounted behind the 
loading point. Data acquisition is undertaken at two samples per second. Testing of a sample can take up to an hour to complete.

The main difference between previous mesh testing and testing using the WASM facilities is the boundary conditions. Previous testing has usually involved restraint of a small panel by plates and bolts at the corners (Tannant et al., 1997; Thompson et al., 1999). In these tests, the mesh invariably slipped relative to the restraint positions and often did not result in rupture of wires and welds prior to large displacements of the central loading point. In practice, panels of mesh are larger than the bolt spacings and some restraint is provided beyond the notional panel restrained by a bolt pattern. It is not feasible to conduct tests on full scale panels of mesh. Therefore, to facilitate comparisons of performance for different mesh types, it was considered best to have consistent boundary restraint conditions that could be replicated for both static and dynamic loading tests.

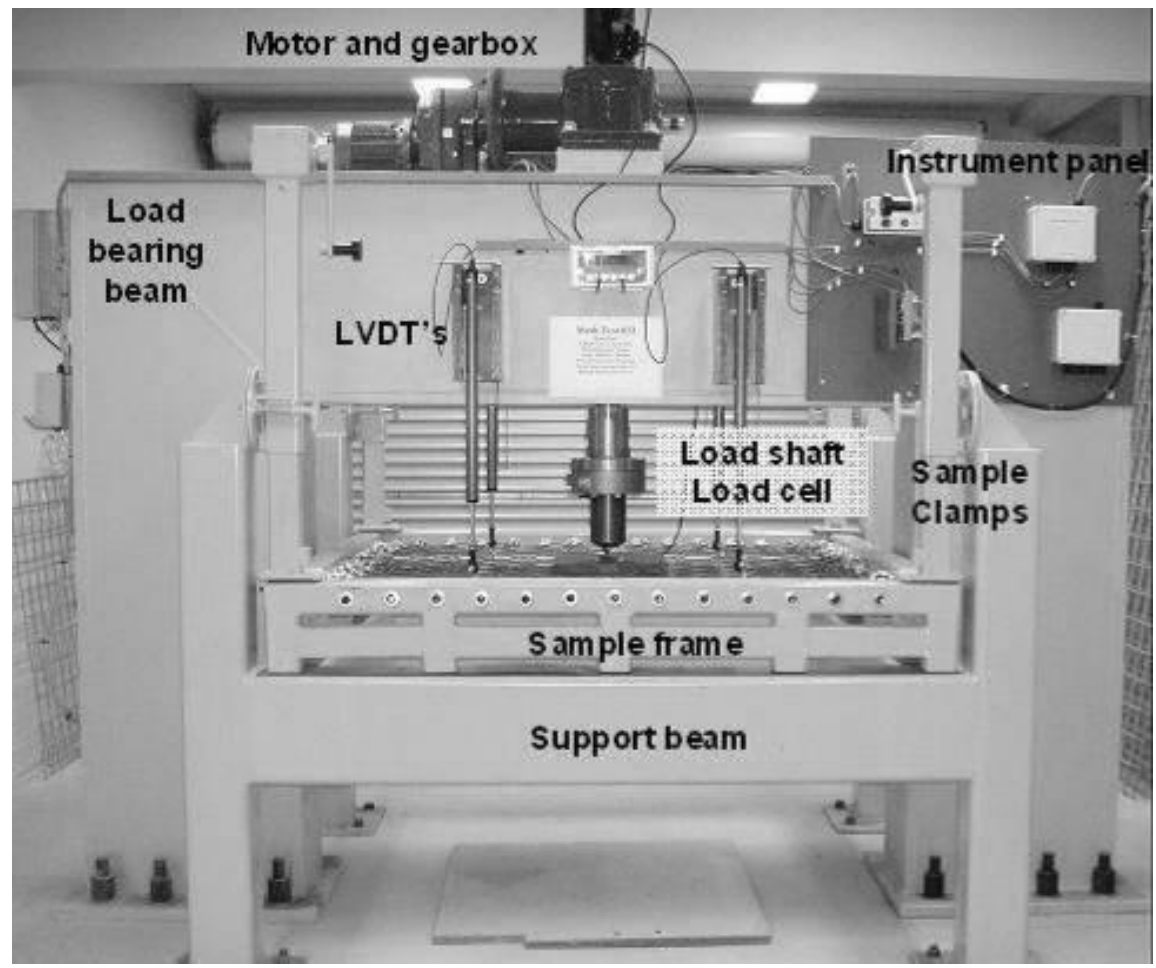

Figure 6 WASM static test facility

The WASM dynamic test facility for mesh is shown in Figure 7. Samples are loaded using the momentum transfer concept (Player et al., 2004; Player, 2012). The mesh testing frame is bolted to a drop beam while the 1.3 by $1.3 \mathrm{~m}$ mesh sample is held in place using threaded bar, shackles and eye bolts in the same configuration as the static test arrangement. A loading mass is placed into the centre of the restrained mesh. The loading mass consists of a pyramid shaped bag filled with a known mass of steel balls $(0.5$ or 1 tonne). The loading area of the bag is $650 \times 650 \mathrm{~mm}$. A wooden prop is placed between the loading mass and the drop beam to prevent the mass 'floating' during the initial free fall period. The drop beam and the attached assembly are dropped from a specific height to generate dynamic loading on the mesh sample. Computer software, advanced instrumentation and a high speed camera are used to record the test data. Data acquisition is undertaken at 25,000 samples per second. Testing is completed in less than a second.

In both static and dynamic testing, the performance of the mesh is characterised by the forcedisplacement response at the centre of the panel. For static tests, the force is measured directly by the load cell shown in Figure 6 and the displacement is inferred from the rate and duration of load application. In dynamic tests, an accelerometer on the loading mass is used to infer the force causing deceleration of the loading mass. The relative displacement between the centre of the panel and its edges is calculated from the instrumentation data recorded during a test. 


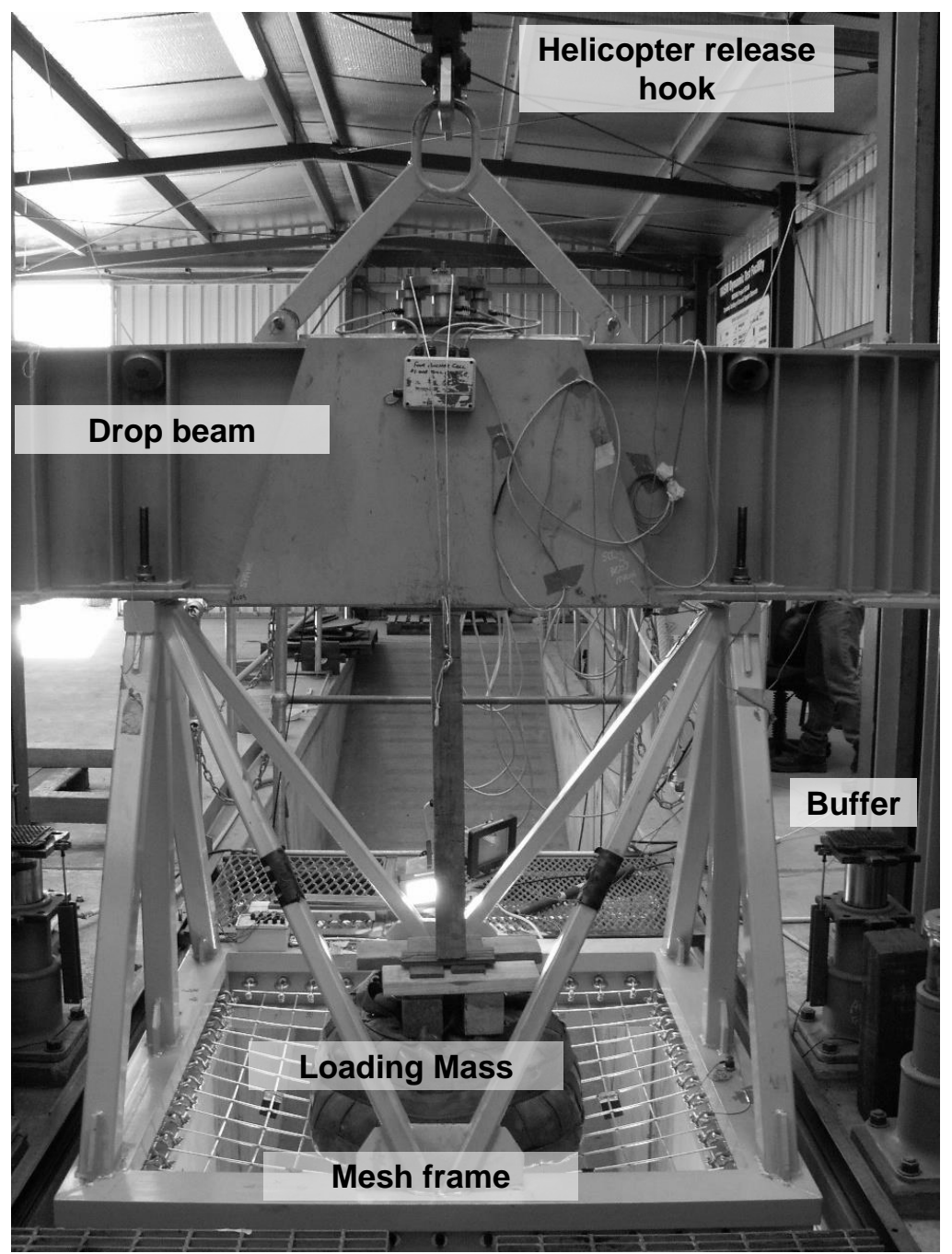

Figure 7 WASM dynamic test facility

\section{$4 \quad$ Energy absorption results}

In the assessment of any ground support system, the relationship between displacement, force and energy must be assessed in relation to the expected ground reactions. The energy absorption is a function of force and displacement. Displacement is influenced, sometimes significantly, by the number of failures within a sample. For this reason, analysis of the mesh types reported here has been undertaken at rupture. Rupture may or may not correspond to the peak force achieved during the test, but the variability of a sample once rupture has occurred means detailed analysis with strong conclusions cannot always be achieved. Typical force-displacement reaction curves for welded wire mesh and chain link mesh are shown in Figure 8 . The failure mechanism of welded wire mesh is a measure of the mesh quality. Three different welded wire mesh failure modes have been identified during laboratory testing at WASM. These can be described as shear failure at the weld points, failure at the heat affected zone (HAZ) and tensile failure of the wire. Failure at the weld is an indication of the weld technology and quality control (dirty electrodes or dirty wire) during mesh manufacturing. Failure at the HAZ is caused by weakening of the wire during the welding process due to excessive weld head pressure and temperature, while tensile failure of the wire is controlled by the wire manufacturing process. Figure 9 shows the different failure modes. For ground support, the preferred mode of failure is at the HAZ or through the wire. Consequently, the weld must be designed to have a strength at least equal to that of the line wire strength (Villaescusa, 1999). 

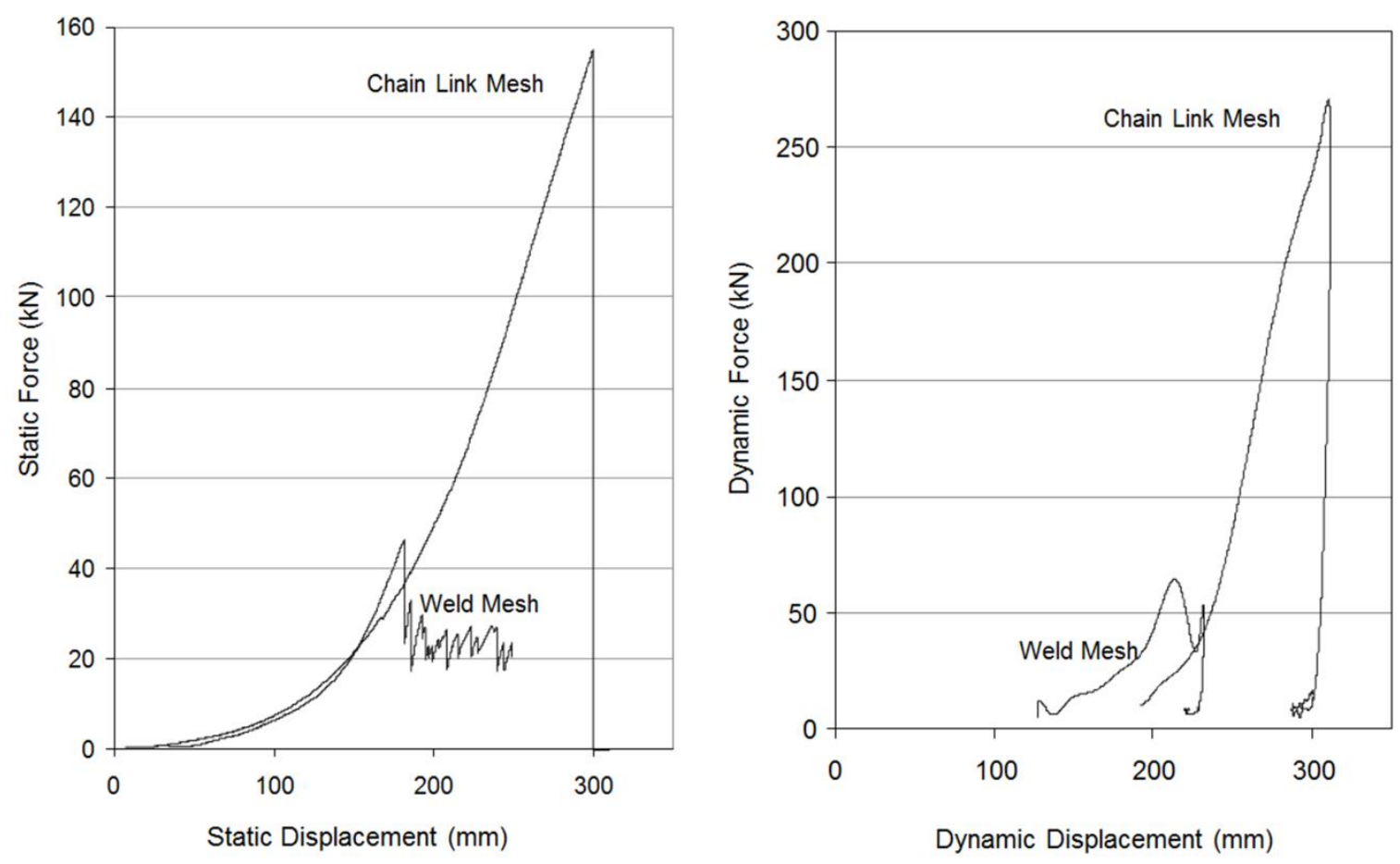

Figure 8 Typical force-displacement reactions for welded wire mesh and woven wire mesh
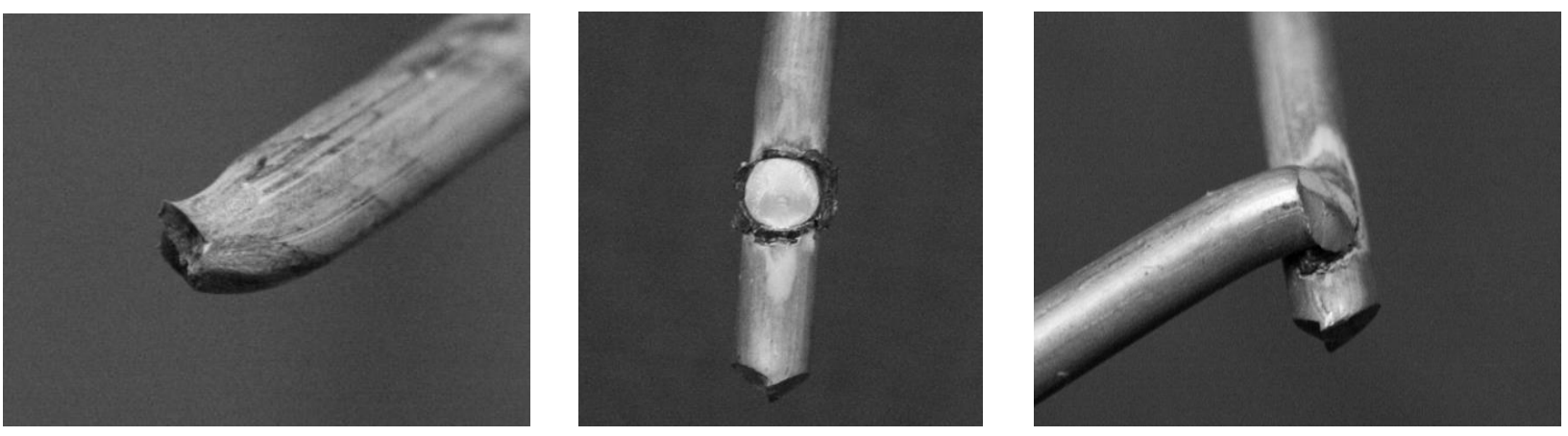

Figure 9 Welded wire mesh failure mechanisms; L - R tensile wire failure, weld failure and failure of the wire through the HAZ

Only one failure mechanism was observed for the woven wire mesh. The mesh failed on the edge of the loading plate either as a result of the plate cutting through the wires or as a result of the wires cutting each other at a 'link'. This failure mechanism limits the accuracy of the test and causes some variability in the results. Generally only one or two strands broke and did not constitute a complete destruction of the mesh.

\section{$5 \quad$ WASM static database}

Figure 10 shows the WASM static database for mesh energy absorption capabilities. The data clearly show that woven mesh has the potential to provide higher energy absorption compared with welded wire mesh. The variability shown is due to the different dimensions and manufacturers of the several products tested at WASM. Most of the data for welded wire mesh comprise the results from testing of $5.6 \mathrm{~mm}$ diameter galvanised wire used typically in the Australian mining industry. 


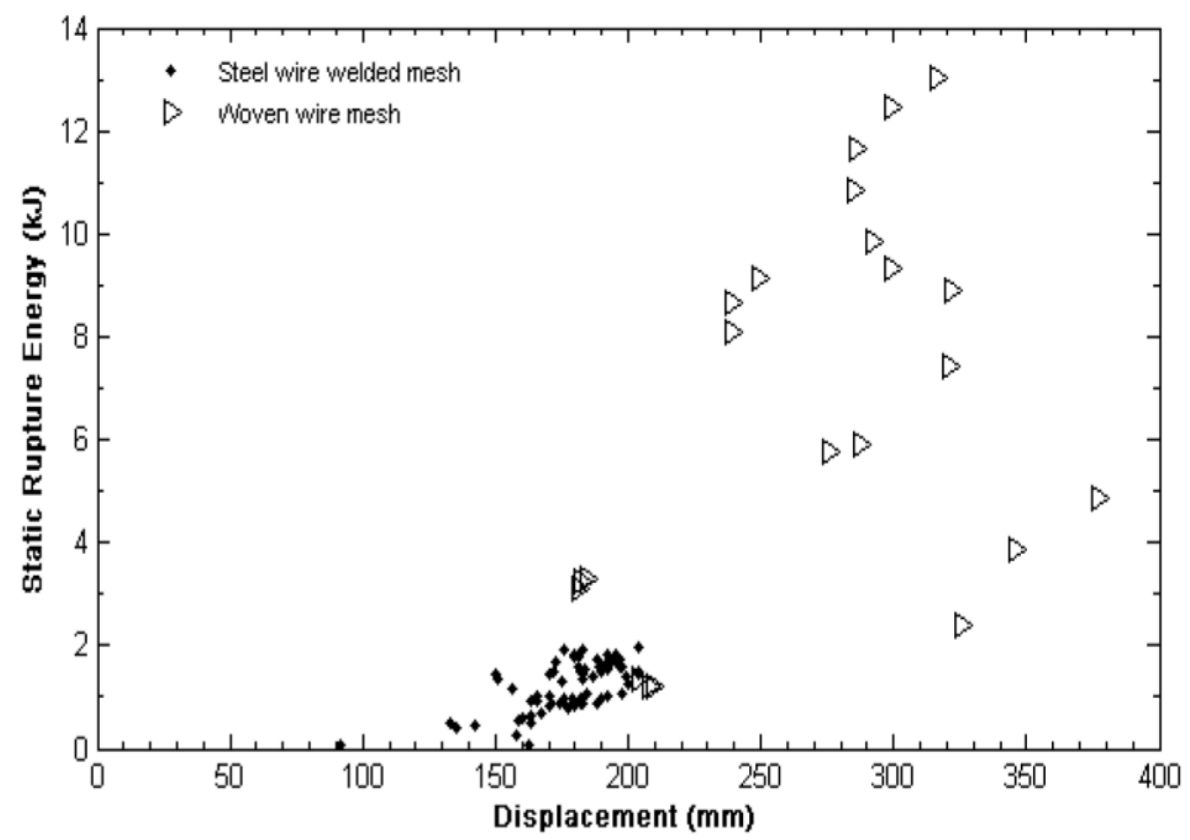

Figure 10 WASM static database for first rupture energy and deformability

\section{WASM dynamic database}

Figure 11 shows the WASM dynamic database of mesh energy absorption. Similarly to the static database results, the woven mesh can absorb more energy than the welded mesh. The large variability for the woven mesh results is due in part to the different products tested. It is also noted that very large deformations were allowed by the 10006 product. When the mesh is exposed at an excavation boundary, such deformations may not be compatible with the reinforcement systems used as part of a complete ground support scheme. On-going research at WASM will investigate the energy absorption of mesh embedded shotcrete incorporating the different mesh types. Because shotcrete cracks in discrete areas, a mesh allowing large deformation may still be suitable, given that a limited portion of the mesh will be required to work. In general, the woven mesh tested to date appears unable to fulfil the $>25 \mathrm{~kJ} / \mathrm{m}^{2}$ required for large energy absorption demand (Thompson et al., 2012). However, research is still on-going.

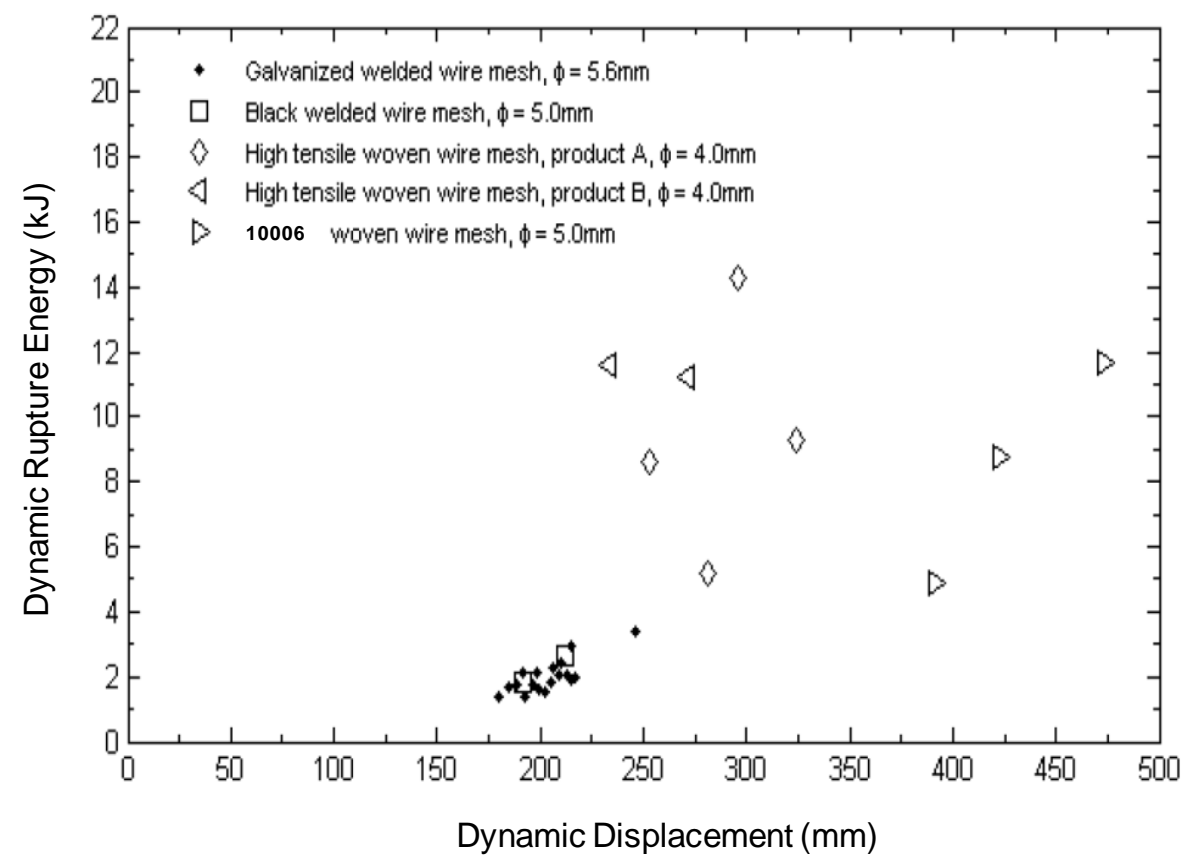

Figure 11 WASM dynamic database for first rupture energy and deformability 
Figure 12 shows a detailed comparison of energy absorption (static and dynamic loading) for $5.6 \mathrm{~mm}$ diameter galvanised welded wire mesh. This is the mesh being used typically in most underground mining applications in Australia. This product, by itself, has not been designed to survive a significant dynamic impact (Table 1). This is particularly important given the role of the failure mode, i.e. potential strength reduction, by failure at the welds. For comparison, a similar plot for woven mesh is presented in Figure 13. A number of non-rupture dynamic results indicate the potential for this product (by itself) to survive at least a medium sized impact.

Table 1 Typical rock mass demand for ground support design (Thompson et al., 2012)

\begin{tabular}{ccccc}
\hline $\begin{array}{c}\text { Demand } \\
\text { Category }\end{array}$ & $\begin{array}{c}\text { Support Pressure } \\
\mathbf{( k P a )}\end{array}$ & $\begin{array}{c}\text { Surface } \\
\text { Displacement }(\mathbf{m m})\end{array}$ & $\begin{array}{c}\text { Plastic Strain } \\
\mathbf{( \% )}\end{array}$ & $\begin{array}{c}\text { Energy } \\
\left(\mathbf{k J} / \mathbf{m}^{\mathbf{2}}\right)\end{array}$ \\
\hline Low & $<250$ & $<50$ & $<1$ & $<15$ \\
Medium & $250-1,000$ & $50-150$ & $1-3$ & $15-25$ \\
High & $>1,000$ & $>150$ & $>3$ & $>25$ \\
\hline
\end{tabular}



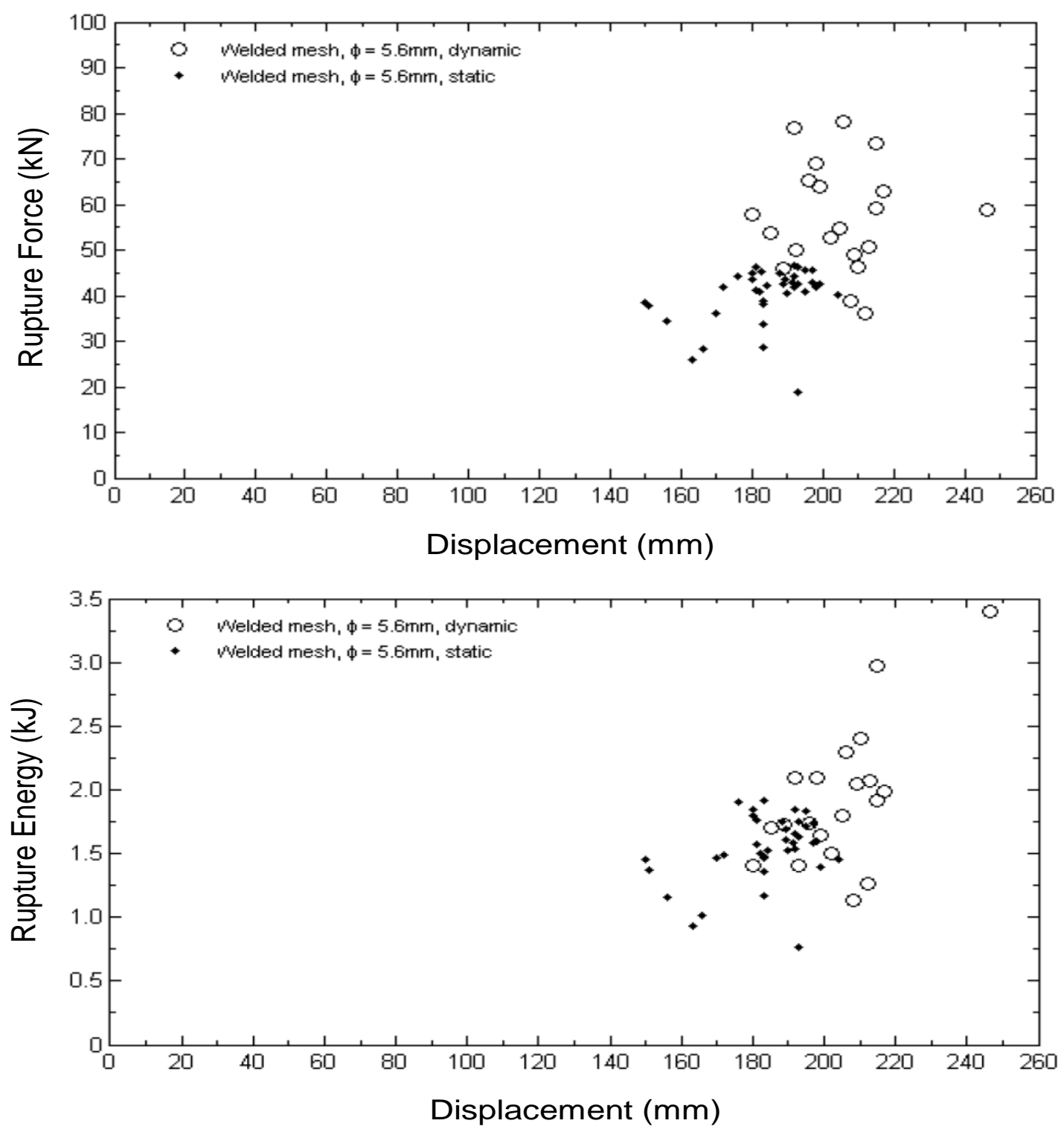

Figure 12 WASM combined static and dynamic databases for $5.6 \mathrm{~mm}$ galvanised welded wire mesh 

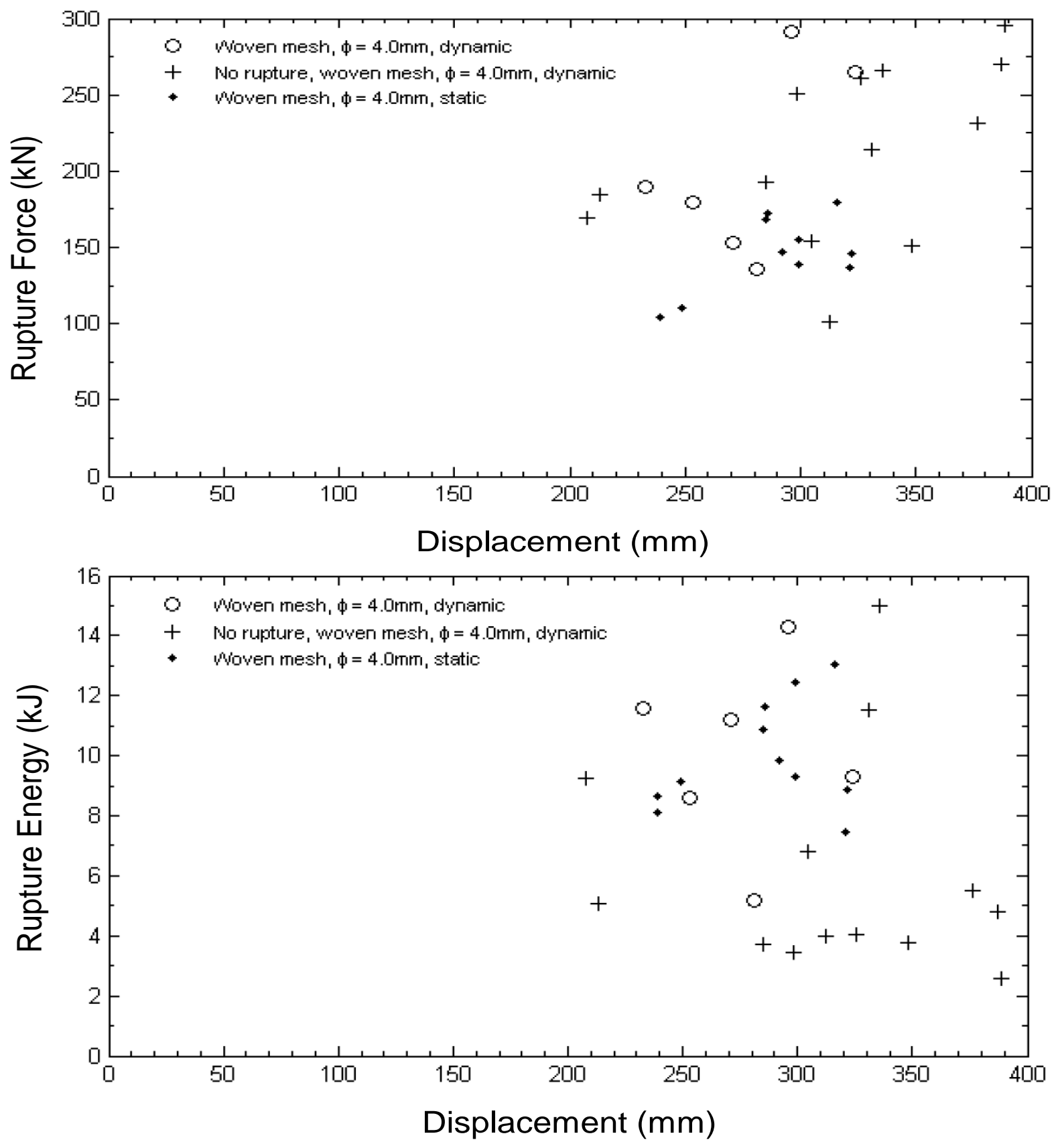

Figure 13 WASM static/dynamic database for woven wire mesh

\section{Conclusions}

The WA School of Mines has developed state of the art static and dynamic testing methodologies of various mesh types for ground support. A large database is now available and the results show good correlation between the facilities. The results show that high tensile woven mesh has much higher energy absorption capabilities compared with the $5.6 \mathrm{~mm}$ diameter galvanised welded wire mesh currently used for ground support in Australia.

\section{Acknowledgements}

The financial assistance of the sponsoring mining companies, MERIWA and the CRC Mining in supporting the work of the WASM Rock Mechanics Group is gratefully acknowledged. 


\section{References}

Coates, R., Brown, S., Bucher, R. and Roth, A. (2009) Fully mechanised installation of high-tensile chain link mesh for surface support in tunnels, in Proceedings First International Seminar on Safe and Rapid Development Mining (SRDM), P. Dight (ed), 6-7 May, Perth, Australia, Australian Centre for Geomechanics, Perth, pp. 165-172.

Morton, E.C. (2009) Static testing of large scale ground support panels, MSc Thesis, Curtin University, 250 p.

Player, J. R. (2012) Dynamic testing of rock reinforcement systems, PhD Thesis, Curtin University, 260 p.

Player, J.R., Morton, E.C., Thompson, A.G. and Villaescusa, E. (2008) Static and dynamic testing of steel wire mesh for mining applications of rock surface support, in Proceedings 6th International Symposium on Ground Support in Mining and Civil Engineering Construction, 30 March-3 April, Cape Town, South Africa, The South African Institute of Mining and Metallurgy, Cape Town, pp. 693-706.

Player, J.R., Villaescusa, E. and Thompson A.G. (2004) Dynamic testing of rock reinforcement using the momentum transfer concept, in Proceedings Fifth International Symposium on Ground support in Mining and Underground Construction, E. Villaescusa and Y. Potvin (eds), 28-30 September, Perth, Australia, Balkema, Rotterdam, pp. 327-339.

Roth, A., Windsor, C.R., Coxon, J. and de Vries, R. (2004) Performance assessment of high tensile wire mesh ground support under seismic conditions, in Proceedings Fifth International Symposium on Ground Support in Mining and Underground Construction, E. Villaescusa and Y. Potvin (eds), 28-30 September, Perth, Australia, Balkema, Rotterdam, pp. 589-594.

Tannant, D., Kaiser, P.K. and Maloney, S. (1997) Load - displacement properties of welded - wire, chain - link and expanded metal mesh, in International symposium on rock support - Applied solutions for underground structures, E. Broch, A. Myrvang and G. Stjern (eds), 22-25 June, Lillehammer, Norway, Norwegian Society of Chartered Engineers, Oslo, pp. 651-659.

Thompson, A.G., Windsor, C.R. and Cadby, G.W. (1999) Performance assessment of mesh for ground control applications, in Proceedings International Symposium on Rock Reinforcement Practice in Mining, E. Villaescusa, C.R. Windsor and A.G. Thompson (eds), 15-17 March, Kalgoorlie, Australia, Balkema, Rotterdam, pp. 119-130.

Thompson, A.G., Villaescusa, E. and Windsor, C.R. (2012) Ground support terminology and classification: An Update, Geotechnical and Geological Engineering, DOI 10 1007/s10706-012-9495-4.

Villaescusa, E. (1999) Laboratory testing of weld mesh for rock support, in Proceedings International Symposium on Rock Reinforcement Practice in Mining, E. Villaescusa, C.R. Windsor and A.G. Thompson (eds), 15-17 March, Kalgoorlie, Australia, Balkema, Rotterdam, pp. 155-159. 